\title{
O Direito Autoral e o Arquiteto
}

\author{
Hildebrando Pontes Neto*
}

Ainda que o façamos sem o instrumental teórico dos especialistas, o presente estudo tem por finalidade abordar aspectos do Direito Autoral que se estendem ao profissional da arquitetura, visando uma maior divulgação dos direitos que o acobertam na qualidade de autor de um projeto arquitetônico.

Em que pese ser amplo o seu campo de atuação, é necessário que o arquiteto conviva mais de perto com os seus direitos para que possa reagir com segurança contra os usurpadores, na sua totalidade convencidos quanto à certeza da impunidade.

\section{O Direito Autoral é conquista constitucional}

A Constituição Federal, no seu art. 153, § 25, ainda que restritivamente, o consagrou:

"Aos autores de obras literárias, artísticas, e científicas, pertence o direito exclusivo de utilizá-las".

Embora garantido pelo texto constitucional e pela lei substantiva civil, o Direito Autoral, pela sua marcada importância na sociedade brasileira moderna, estava a reclamar um tratamento mais adequado.

$\mathrm{E}$ tanto se fazia sentir essa necessidade, que o nosso legislador, ainda que com atraso, acabou por fazer incorporar à nossa constelação de leis, a de $\mathrm{n}^{\circ} 5.988$ de 14 de dezembro de 1973, reguladora dos direitos autorais.

Conquanto apresente falhas ou imperfeições, e elas existem, é contudo de grande realce para as questões autorais brasileiras a sua vigência a partir de $1^{\text {o }}$ de janeiro de 1974 .

Ampliou substancialmente o território do Direito Autoral, até o seu advento confinado nos estreitos limites do Código Civil de 1916,

- Hildebrando Pontes Neto é advogado militante em Belo Horizonte - Minas Gerais, e Membro do Conselho Nacional de Direito Autoral, órgão do Ministério da Educação e Cultura. 
premido entre o Direito das Obrigações e das Coisas, cristalizado no tempo, divorciado de uma efervescente realidade fática de transformações rápidas e significativas.

Com o novo regulamento, no entanto, o legislador devolveu ao Direito Autoral brasileiro a contemporaneidade de que necessitava, armando-o de uma melhor sistemática, possibilitando-o cumprir com mais eficácia a tarefa de proteger o autor de obras intelectuais.

Graças ao seu revigoramento, o campo de atuação do arquiteto encontra-se legalmente protegido, como veremos.

No caso específico do trabalho de criação intelectual do arquiteto, a Lei 5.194, de 24 de dezembro de 1966, que ordena o exercício das profissões de Engenheiro, Arquiteto, Engenheiro Agrônomo, por conseguinte, anterior à Lei 5.988, já previa no seu Capítulo II, Da Responsabilidade e Autoria, em seu art. 17 que:

"os direitos de autoria de um plano ou projeto de engenharia, arquitetura ou agronomia, respeitada as relações contratuais expressas, são do profissional que os elaborar."

$\mathrm{E}$ o artigo seguinte:

"As alterações de projeto ou plano original só poderão ser feitas pelo profissional que o tenha elaborado'

Assim, desde a vigência da Lei 5.194, os direitos de autoria de um projeto arquitetônico pertenciam ao seu autor, e só a ele, o direito de modificá-lo.

Ora, se a Lei 5.194, de finalidade diversa, estabelecia o direito de autoria de maneira casuística, com maior clareza e rigor deveria fazê-lo a Lei 5.988, específica em matéria autoral.

$\mathrm{E}$ fê-lo até certo ponto a contento, oferecendo conceituações acertadas, outorgando aos arquitetos proteção.

Incorporou ao seu texto o projeto arquitetônico como obra intelectual, uma criação do espírito:

"São obras intelectuais as criações de espírito, "ie qualquer modo exteriorizadas, tais como:

$\mathrm{X}$ - os projetos, esboços e obras plásticas, concernentes à geografia, topografia, engenharia, arquitetura, cenografia e ciência".

Outro não poderia ter sido o procedimento do nosso legislador.

A elaboração arquitetônica, que se exterioriza no projeto, é a a forma que o arquiteto tem de exprimir o infinito humano através de um objeto concreto, aliada a uma apurada sensibilidade. 
$\hat{E}$ antes de mais nada um dado de cunho pessoal, de características inconfundíveis, onde se instala o poder de criação de seu autor.

Não fora assim, inexistiria o espaço unitário das igrejas românicas e o espaço plural das igrejas góticas.

Desconheceríamos a universalidade da Catedral de Brasília.

Consagrado o projeto arquitetônico como obra intelectual protegida, daí decorre que o seu autor é titular de direitos morais e patrimoniais.

Diz o art. 21:

"O autor é titular de direitos morais e patrimoniais sobre a obra intelectual que produziu".

Equivale dizer, que o direito do autor pode ser visto através de dois primas distintos, um diferente do outro, porém, intimamente ligados, em permanente relação de interdependência: o primeiro, de ordem pessoal (direito pessoal); o segundo, de ordem patrimonial ou pecuniário (direito patrimonial). É portanto um instituto jurídico de duplo reflexo: direito pessoal e direito real.

Embora não seja objeto específico deste estudo, ainda que de passagem, fixaremos a diferença entre direto pessoal e real, cuja conceituação levará, por certo, a um melhor entendimento dos direitos morais e patrimoniais sobre a obra de criação.

Assim é, que:

"Direito Pessoal, por seu turno, conceitua-se como relação jurídica mercê da qual ao sujeito ativo assiste o poder de exigir do sujeito passivo determinada prestação, positiva ou negativa".

$E$,

"O direito real pode, destarte, ser conceituado como a relação jurídica em virtude da qual o titular pode retirar da coisa, de modo exclusivo e contra todos, as utilidades que ela é capaz de produzir". (Barros Monteiro, WASHINGTON - Curso de Direito Civil - Direito das Coisas -, $3^{\circ}$ vol., pág. 12, Edição Saraiva).

No primeiro, ressalta inconfundível a relação entre pessoas; no segundo, é a relação de poder do indivíduo sobre a coisa.

Tem-se observado com certa freqüência o aumento considerável de violações dos projetos arquitetônicos, sem que, na prática, o arquiteto lute por manter a integridade de sua obra, disparando os dispositivos legais colocados à sua disposição pelo legislador.

Com isso, perde a oportunidade de criar condições objetivas para que seja afastada de seu meio de trabalho essa prática indesejável. 
Antônio Chaves define o direito moral como sendo "o direito que tem o autor de ver reconhecida a sua "paternidade" da obra, de ver preservada a intangibilidade da mesma, no sentido de que não possa ser modificada, alterada, mutilada ou adaptada, a não ser mediante o seu expresso consentimento. É como que o reflexo da sua personalidade na parte mais nobre, que é a atividade criadora" (Direito de Autor do Arquiteto, do Engenheiro, do Urbanista, do Paisagista, do Decorador - RT 433/12).

A Lei 5.988, estabeleceu as pressupostos de direito moral no art. 25 e incisos:

"São direitos morais do autor:

I - o de reivindicar, a qualquer tempo, a paternidade da obra;

II - o de ter o seu nome, pseudônimo ou sinal convencional, indicado ou anunciado, como sendo o do autor, na utilização;

III — o de conservá-la inédita;

IV - o de assegurar-lhe a integridade, opondo-se a quaisquer modificações, ou à prática de atos que, de qualquer forma, possam prejudicá-la, ou atingí-lo, como autor, em sua reputação ou honra;

$\mathrm{V}$ - o de modificá-la, antes ou depois de utilizada;

VI — o de retirá-la de circulação, ou de lhe suspender qualquer forma de utilização já autorizada".

De acordo com o texto da lei integram o direito moral como elementos constitutivos os direitos relativamente à paternidade, ao ineditismo, à integridade, à modificação, ao arrependimento:

Paternidade - é o direito que tem o autor de pleitear a ligação de seu nome à obra criada. Através dele, o nome do autor terá que estar associado à obra no momento de sua utilização reprodução ou execução. Por outro lado, pode o autor impedir a vinculação de seu nome a própria obra. Verifica-se, pois, que o direito à paternidade confere ao seu titular o direito a publicação de uma determinada obra como sendo de sua autoria.

Inédito - é um direito exclusivo do autor de decidir sobre a divulgação ou não de seu trabalho artístico. É um direito personalíssimo.

Integridade - é o direito que confere ao autor a possibilidade de manter a inteireza de sua obra, colocando-a a salvo das violações perpetradas. E toda vez que a obra é adulterada, sobre o autor prejuízos em sua reputação ou honra.

Modificação - é o direito que tem o autor de modificar a sua obra. As alterações que pretender realizar poderão ocorrer antes ou depois da obra utilizada. 
Arrependimento - é o direito que permite ao autor alterar obra sua já publicada ou impedir a sua circulação retirando-a do comércio.

Nunca é demais lembrar que as violações do direito moral do autor vão atingir, via de regra, a paternidade, a integridade e a divulgação da obra.

Afora as disposições previstas pelo art. 25 e incisos sobre o direito moral - e diga-se ligeiramente destacadas - o legislador cuidou de inserir na lei artigo específico sobre o direito de que dispõe o autor do projeto arquitetônico de repudiar ou não a paternidade da concepção da obra modificada pelo dono da construção executada:

"Art. 27 - Se o dono da construção executada, segundo projeto arquitetônico por ele aprovado, nela introduzir alterações, durante sua execução ou após a conclusão, sem o consentimento do autor do projeto, poderá este repudiar a paternidade da concepção da obra modificada, não sendo lícito ao proprietário, a partir de então e em proveito próprio dá-la como concebida pelo autor do projeto inicial".

Trata-se, portanto, do direito ao repúdio.

Se o autor, pela lei, tem o direito de manter indissoluvelmente ligado seu nome à obra, bem como impedir que sua integridade seja violada, com maior razão terá o direito de repudiá-la quando alterada sem o seu consentimento. punha:

$\mathrm{E}$ cabe aqui ressaltar que a Lei 5.194 , em seu art. 18 já dis-

"As alterações do projeto ou plano original só poderão se1 feitas pelo profissional que o tenha elaborado".

$\mathrm{E}$ o parágrafo único do mesmo artigo:

"Estando impedido ou recusando-se o autor do projeto ou plano original a prestar sua colaboração profissional, comprovada a solicitação, as alterações ou modificações deles poderão ser feitas por outro profissional habilitado, a quem caberá a responsabilidade pelo projeto ou plano modificado".

Qualquer que seja a modificação a ser feita no projeto arquitetônico terá que ter o consentimento do seu autor.

$\mathrm{E}$ caso não seja mantido o projeto original, tem $\mathrm{o}$ arquiteto $\mathrm{o}$ direito de repudiar a paternidade da sua concepção, impedindo que o seu nome fique vinculado a um projeto diferente daquele que criou.

Vê-se, portanto, que o art. 27 da Lei 5.988 veio complementar o art. 18 e parágrafo único da Lei 5.194. 
Em seguida ao art. 27 que pode ser considerado como que um acréscimo, um plus ao direito moral do arquiteto, o legislador prescreveu no art. 28:

"Os direitos morais do autor são inalienáveis e irrenunciáveis"

O fato do autor ceder os direitos patrimoniais sobre uma determinada obra, não implica que ele esteja promovendo a cessão dos seus direitos morais.

Pela sua própria natureza são inalienáveis e irrenunciáveis.

Já se disse que o direito do autor é um instituto jurídico de duplo reflexo: direito pessoal e real.

Em que pese diferirem um do outro, estão intimamente entrelaçados. Configurada a violação ao direito moral, irreversivelmente ela se estende ao direito patrimonial consoante os arts. 29 e 30:

"Cabe ao autor o direito de utilizar fruir e dispor de obra literária, artística ou científica, bem como autorizar sua utilização ou fruição por terceiros, no todo ou em parte".

Em seguida:

"Depende de autorização do autor de obra literária, artística ou científica, qualquer forma de utilização assim como."

Antônio Chaves ensina que "direito pecuniário é, ao invés, aquele que permite ao autor retirar todos os proventos de ordem patrimonial que a obra possa proporcionar, mediante a sua colocação à disposição do público para fins de rendimento econômico" (Direito de Autor, do arquiteto, do engenheiro, do urbanista, do paisagista, do decorador", RT 433/13.

E mais,

"Tem o arquiteto o direito de exclusividade, isto é, de sosomente ele tirar de sua obra os proventos pecuniários que ela possa proporcionar, e de não permitir sua utilização por terceiros por nenhuma forma remunerada, sem sua cessão ou autorização". (Direito de Autor, do arquiteto, do engenheiro, do urbanista, do paisagista, do decorador", RT $433 / 19)$.

Equivale dizer que direito patrimonial e exploração econômica da obra pelo seu autor são a mesma coisa.

O legislador estabeleceu através da Lei 5.988, a forma pela qual poderá o autor ceder os seus direitos sobre a obra que criou:

"Art. 52 - Os direitos do autor podem ser, total ou parcialmente, cedidos a terceiros por ele ou por seus sucessores, a 
título universal ou singular, pessoalmente ou por meio de representante com poderes especiais.

Parágrafo único - Se a transmissão for total, nela se compreendem todos os direitos do autor, salvo os de natureza personalíssima, como de introduzir modificações na obra, e os expressamente excluídos por lei"

O objeto da cessão ficará circunscrito aos direitos patrimoniais, porquanto os direitos morais são inalienáveis e irrenunciáveis.

$\mathrm{E}$ o art. 53 prescreve de que forma deverá ser feita a cessão dos direitos do autor:

"A cessão total ou parcial dos direitos do autor, que se fará sempre por escrito, presume-se onerosa.

$\S 1^{\circ}$ - Para valer contra terceiros, deverá a cessão ser averbada à margem do registro a que se refere o art. 17 .

$\S 2^{\circ}$ - Constarão do instrumento do negócio jurídico, especificamente, quais os direitos objeto de cessão, as condições de seu exercício quanto ao tempo e ao lugar e, se for a título oneroso, quanto ao preço ou retribuição".

Na cessão, o coeficiente (titular do direito), transfere ao cessionário o direito de exploração da obra.

As condições, preço, tempo e lugar deverão ficar de tal forma estabelecidas que não deverão gerar a mais mínima dúvida, para o autor da obra. A cessão presume-se sempre onerosa.

O que diz o art. 17 da Lei 5.988?

"Para segurança de seus direitos, o autor da obra intelectual poderá registrá-la, conforme sua natureza, na Biblioteca Nacional, na Escola de Música, na Escola de Belas Artes da Universidade Federal do Rio de Janeiro, no Instituto Nacional de Cinema, ou no Conselho Federal de Engenharia, Arquitetura e Agronomia".

O verbo usado pelo legislador não tem caráter imperativo. Ao contrário, sugere uma faculdade.

Pela redação do texto, não fica o autor arquiteto obrigado a registrar a sua obra junto ao Conselho Federal de Engenharia, Arquitetura e Agronomia.

Caso fosse outra a intenção do legislador, por certo teria estabelecido que o autor de obra intelectual só asseguraria os seus direitos promovendo o respectivo registro.

Por outro lado, o parágrafo $1^{\circ}$ do art. 53 prescreve que a cessão, para valer contra terceiros, deverá ser observada à margem do registro a que se refere o art. 17. 
O verbo ali empregado não subentende faculdade: a cessão deverá ser, indica obrigatoriedade, império.

Pelos dispositivos cotejados, pode-se estabelecer um raciocínio de que o contrato de cessão, configurando e garantindo o direito do arquiteto, prevalecerá, contra terceiros, somente se for averbado a margem do registro.

A Resolução n: 260 de 21.04.79, estabeleceu normas para o registro de obras intelectuais no Conselho Federal.

$\mathrm{E}$ fê-lo, com base no art. 17 da Lei 5.988 , e porque não dizer, acompanhando a redação do parágrafo $1^{\circ}$ do art. 53 .

Estabeleceu no art. 1\% que:

"Os autores de projetos, esboços e obras plásticas, concernentes à geografia, topografia, engenharia, arquiletura, cenografia e ciência poderão registrá-los no Conselho Federal de Engenharia, Arquitetura e Agronomia".

A Resolução diz que os autores poderão.

Através dela também, não estão os autores arquitetos obrigados ao registro.

Resta então uma explicação que afasta em definitivo qualquer idéia de contradição aparente entre os dispositivos citados. O contrato entre partes dispensa publicidade. Os contratantes sabem o que pactuaram. Mas para que a cessão tenha validade contra terceiros será sempre necessário a sua averbação. O registro e a averbação é no nosso entender uma forma de revigoramento do direito do autor.

Outro aspecto de importância, de verdadeiro realce, tem em vista o que preceitua o art. 36 da Lei 5.988:

"Se a obra intelectual for produzida em cumprimento a dever funcional ou a contrato de trabalho ou de prestação de serviços, os direitos do autor, salvo convenção em contrário, pertencerão a ambas as partes, conforme for estabelecido pelo Conselho Nacional de Direito de Autor".

E para uma melhor compreensão dos reflexos práticos decorrentes da aplicabilidade do art. 36, torna-se necessário uma visão do sistema que rege as relações entre o comitente (empregador) e o comissário (empregado).

$\mathrm{O}$ princípio que rege as relações de contrato reside na vinculação das partes mediante o princípio da autonomia da vontade. $\hat{\mathrm{E}} \mathrm{um}$ sistema.

O outro, o do direito do trabalho ou administrativo. Neste caso, a relação entre partes se submete a normas e princípios do direito autoral em virtude das obras de criação daí resultantes. 
"Sob este prisma, a encomenda pode, pois, estar ligada à prestação do serviço em geral ou à relação de emprego ou função". (Direito de Autor na Obra Feita sob Encomenda, pág. 117).

O fato é que esse dispositivo tem sofrido as mais viáveis críticas ao nosso ver justas, não só pela sua redação ambígua, mas acima de tudo pela fluidez que o seu texto encerra.

Eduardo J.V. Manso ao enfocar a posição reservada ao Conselho Nacional de Direito de Autor, o vê exercendo "funções de partidor desse direito, a fim de dizer em que proporções esses esdrúxulos condôminos serão seus titulares, e quais os quinhõ̃es que cada qual terá sobre tal obra". (A obra de autor assalariado, pág. 11). Segundo Carlos Alberto Bittar: "O texto é passível de censura também por sua indefinição: não enuncia a quem pertencerão os direitos patrimoniais sobre a obra encomendada, ao contrário de inúmeras leis especiais". (Direito de Autor na Obra Feita sob Encomenda, pág. 127).

Para José de Oliveira Ascensão, o art. 36 estabeleceu uma regra principal e outra subsidiária.

“A regra principal é a da prevalência da autonomia da vontade, e está contida na expressão "salvo convenção em contrário"."

Cabe às partes disporem livremente sobre a forma através da qual vão tratar o direito do autor. É a regra principal.

"Se não houver acordo, a obra pertence a ambas as partes. Cria-se assim uma forma de co-autoria. Mas como posição de ambas perante a obra não é idêntica, diversos também os poderes, que lhes cabem. Temos pois uma espécie de comunhão irregular, uma contitularidade em que será particularmente difícil determinação dos poderes que cabem a cada sujeito".

Ascensão menciona a terceira regra complementar da anterior: "Cabe ao Conselho Nacional de Direito Autoral estabelecer os termos em que os direitos pertencem às partes".

Entendemos que a solução adotada pelo legislador é extremamente infeliz. A lei deveria definir o titular da obra de encomenda.

Não enfrentou essa responsabilidade, bipartiu o direito entre o encomendante e o comissário.

Com isso, dificultou a aplicação do dispositivo, transferindo para o Conselho Nacional de Direito Autoral a responsabilidade de solucionar as dificuldades daí decorrentes.

Antônio Chaves em a "Nova Lei Brasileira de Direito de Autor", pág. 31, comentando o art. 36, diz que:

"Afastou-se, assim, a lei do direito de autor, do critério seguido pelo Código de Propriedade Industrial, Lei 5.772 de 21.12.71, que no 
art. 40 atribui exclusivamente ao empregador os inventos, bem como os aperfeiçoamentos realizados durante a vigência de contrato expressamente destinado à pesquisa no Brasil, em que a atividade inventiva do assalariado ou do prestador de serviços seja prevista, ou ainda que decorra da própria natureza da atividade contratada".

$\mathrm{E}$ mais,

"Não vê razão Newton Silveira, "A Nova Lei dos Direitos do Autor", in "RT Informa", $\mathrm{n}^{\circ} 99$, de 15.02.74, pág. 22, para tratamento diverso dos direitos sobre a criação do empregado ou prestador de serviços, quando se trate de invenção ou de criação de caráter artístico".

As obras literárias, artísticas e científicas diferem dos inventos e desenhos industriais.

As primeiras apresentam um fim estético, as segundas um fim industrial.

José Carlos Tinoco Soares, afirma que "não se pode permitir a interferência do direito do autor nos modelos industriais e vice-versa, pelas finalidades distintas que apresentam" (Regime das Patentes e dos Royalties, Revista dos Tribunais, 1972, SP).

Segundo Carlos Alberto Bittar, "a obra individual de assalariado é aquela produzida por autor remunerado justamente para a elaboração de trabalhos intelectuais, em que o encomendante (o empregador: pessoa natural ou jurídica, de direito privado ou de direito público), assume os riscos da reprodução e da divulgação e fornece os meios materiais para a sua consecução. Define, de regra, o plano e orienta a execução da obra.

O autor trabalha sob a direção do empregador, respeitando, pois, os regulamentos próprios da empresa e seguindo a orientação nela traçada.

As partes vinculam-se por contrato de trabalho ou através de relação funcional, conforme se trate de empresa privada ou de ente público, obedecidos os princípios e normas do direito do autor aplicáveis quanto à obra produzida" (Direito de Autor na Obra Feita sob Encomenda, págs. 143/144).

O autor é contratado mediante salário para criar para o empregador. É natural, pois, que os direitos patrimoniais sejam atribuídos a ele, que remunera o seu empregado para obter o resultado de seu trabalho.

"Referindo-se a diferentes sistemas (Inglaterra, França, Estados Unidos, Portugal, Bulgária, Marrocos, Itália) - que conferem ao empregador direitos de utilização da obra criada sob contrato de trabalho, nos limites das necessidades da atividade própria da empresa - Eduardo J.V. Manso assinala que essa diretriz se fundamenta na teoria do enriquecimento ilícito. Acentua que se esteia no princípio geral segundo o qual o enriquecimento de um não pode causar injus- 
tamente o empobrecimento do outro. Assim, na obra encomendada sob contrato de trabalho, ao empregador incumbe arcar com todos os custos da realização, que se opera no âmbito de sua própria organização, com os recursos de seu estabelecimento e com fruição de bens de seu patrimônio. Anota ainda, que, muitas vezes, o empregador contribui com idéias e planos, desenvolvendo trabalho intelectual, fornecendo meios e recursos para a consecução da obra. Seria, pois, contrário ao citado princípio não se reconhecerem os direitos patrimoniais do empregador, sem cuja participação a obra não chegaria a existir". (Direito de Autor na Obra Feita sob Encomenda, págs. 149/150).

"Assim por exemplo, o escritor, o compositor, o poeta, o desenhista, o arquiteto, o novelista ou outro profissional assalariado conservarão os direitos não compreendidos na atividade específica da empresa ou que escapem à utilização própria a que a obra se destine".

"No caso do arquiteto, não pode a construtora utilizar, depois, sem autorização e remuneração do autor, o plano concebido em finalidades distintas do respectivo ajuste" (Direito de Autor na Obra Feita sob Encomenda, pág. 150).

O encomendante ao utilizar uma obra não poderá atropelar a finalidade da encomenda. O que ultrapassá-la há de permanecer com o empregado.

É de se ressaltar a importância dos arts. 80 e 81 da Lei 5.988/73.

"Salvo convenção em contrário, o autor de obra plástica, ao alienar o objeto em que ela se materializa, transmite ao adquirente o direito de reproduzí-la, ou de expô-la ao público".

“A autorização para reproduzir obra de arte plástica, por qualquer processo, deve constatar de documento, e se presume onerosa".

A obra de arquitetura embora seja considerada como obra de arte plástica — os arts. mencionados estão contemplados no Capítulo III da Lei 5.988, sob o título: Da utilização de obra de arte plástica, não pode ser vista debaixo do mesmo regime em decorrência de sua própria natureza.

Para mim, o trabalho de criação do arquiteto difere da obra de arte plástica em virtude de características especiais.

A obra arquitetônica ainda que se manifeste embrionariamente na planta, nos desenhos, esboços, vai se corporificar na edificação da casa, do prédio.

Para Eduardo Vieira Manso, "a obra arquitetônica, quando alienada sem a ressalva do art. 80 da Lei 5.988, transmitirá ao adquirente o direito de reproduzí-la. 


\section{6}

E se a construção de uma segunda obra arquitetônica por uma reprodução daquela originariamente adquirida, o proprietário desta estará livre para reproduzí-la e, evidentemente, explorá-la sem que o arquiteto possa opor-se a isso (Direito Autoral, pág. 61).

Quanto a questão da reprodução de obras de arte existentes nos logradouros públicos, o art. 49, inciso I, letra e, quando diz que não causa ofensa aos direitos do autor a reprodução de obras de arte existentes em logradouros públicos, agravou a situação do direito de reprodução do autor arquiteto. Por exemplo: a fachada de um edifício que corporifica a obra de arquitetura como manifestação estética poderá ser utilizada por qualquer pessoa. 